\title{
Automated methodology for adjustment of component values in passive converter circuit for wind turbine generators
}

\author{
A. Van den Bossche ${ }^{1}$, A. St. Marinov², P. V. Yankov ${ }^{3}$ E. B. Bekov ${ }^{4}$ \\ ${ }^{1}$ Ghent University, Ghent, Belgium, alex.vandenbossche@ugent.be \\ ${ }^{2}$ Technical University - Varna, Varna, Bulgaria, a.marinov@tu-varna.bg \\ ${ }^{3}$ Technical University - Varna, Varna, Bulgaria, plamenvalentinov@gmail.com \\ ${ }^{4}$ Technical University - Varna, Varna, Bulgaria, emo_bekov@hotmail.com
}

\begin{abstract}
The current paper proposes an automated design approach for a previously developed passive converter circuits for wind turbine generators. This suggested approach allows to calculate the components for all passive converter circuits approved in European patent number PCT/EP2010/055637, where only minor changes in the source code of the mathematical and simulation software have to be made when different circuits are involved. An optimisation based on steepest descent method results in power/frequency (power/speed) curve that matches well the cubic dependence $\left(P_{\mathrm{wtmax}} \sim \omega^{3}\right)$ of the extracted power.
\end{abstract}

Keywords - Converter circuit, Simulation, Wind energy.

\section{INTRODUCTION}

It is a valid fact that wind turbines are most efficient in variable speed mode [1-4]. The first electrical conversion $\mathrm{AC} / \mathrm{DC}$ from the three phase generator has key role in the energy extraction. An active or passive rectifier will determine the type of electrical control that is used in the system. Usually the use of single three phase uncontrolled full wave rectifiers (passive) is limited to low power applications. An advantage is the lack of complicated control unit which significantly reduces the design time and the final price. Disadvantage is the poor electrical efficiency compared with the fully controlled thyristor or transistor rectifiers or so-called active.

A novel design for passive converter circuit (fig. 2.) improves the overall efficiency. The circuit includes the following components: two 3-phase full bridge uncontrolled rectifiers build with diodes $\mathrm{D} 1 \div \mathrm{D} 12$, external inductors $\mathrm{L}_{\text {ext1 }} \div \mathrm{L}_{\text {ext3 }}$ and a simplified model of the permanent magnet synchronous generator consisting of voltage source $\mathrm{V} 1 \div \mathrm{V} 3$ and inductor $\mathrm{L}_{\text {gen } 1} \div \mathrm{L}_{\text {gen } 3}$ for every single phase. The modeling of a power/frequency curve of a wind turbine with PMSG and passive converter is done by specifically developed methodology. It includes parametrical optimization of the values of $\mathrm{L}_{\text {ext }}$ and $\mathrm{L}_{\text {gen. }}$. As a result the power/frequency curve should match the well-known cubic dependence $\mathrm{P}_{\mathrm{wtmax}} \sim \omega^{3}$ [5].

This basic circuit from the European patent PCT/EP2010/055637, offers performance which can compete with the fully controlled rectifiers in yearly energy yield. The scientific study of the circuits led to a conclusion that there is decrease of the efficiency of just several percent compared with the active ones [5]. Figure
1 shows the simulation of the modeled circuit, done in Capture CIS, which graphically explains why there is such a difference. First curve $\mathrm{P}_{\mathrm{w}}$ (dashed) is representing the cubic dependence of the extracted power, it is used as guideline. As it can be seen the simulation curve $\mathrm{P}$ of the output power deviates at the middle area from $\mathrm{P}_{\mathrm{W}}$ causing the drop in the power yield. Still the improved passive converter circuit betters the efficiency of the conventional three phase uncontrolled rectifier with output curve $\mathrm{P}_{\mathrm{C}}$.

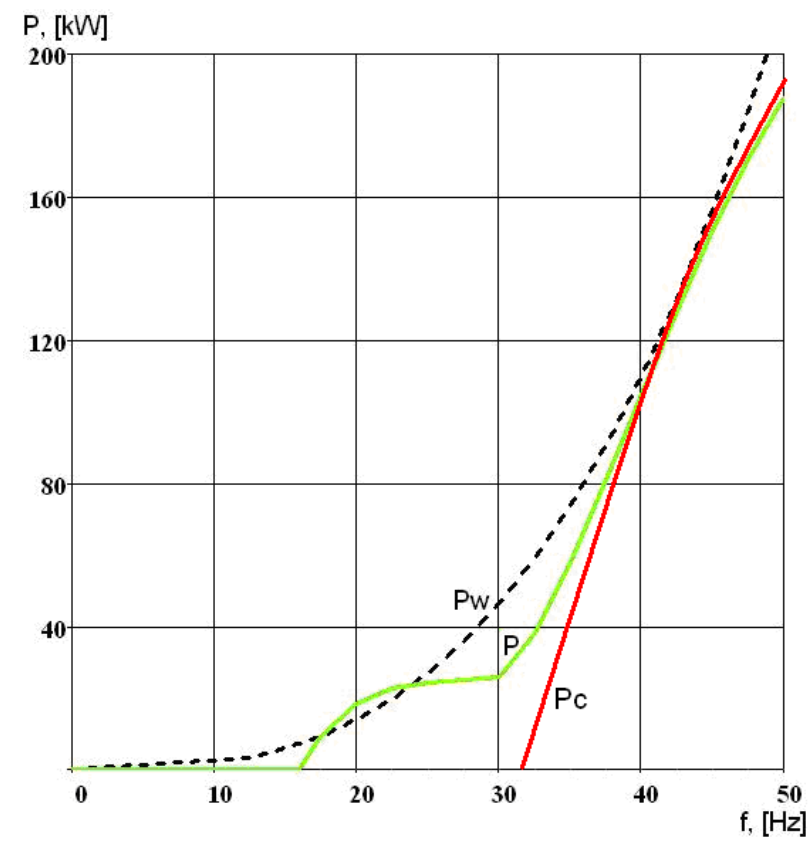

Fig. 1. Obtained Power/Frequency curve from three phase passive converter.

For the creation of every single curve, a following sequence is used: first an analog circuit is created in "Capture CIS". Then the points of the power/frequency curve are evaluated from PSpice. Last step is connecting those points and generating graphic in any mathematical software product such as MS Excel, MathCAD, etc.

Simulations are performed until the obtained curve is with acceptable values for the obtained output power. Numerous iterations for each circuit can increase significantly the design time. 


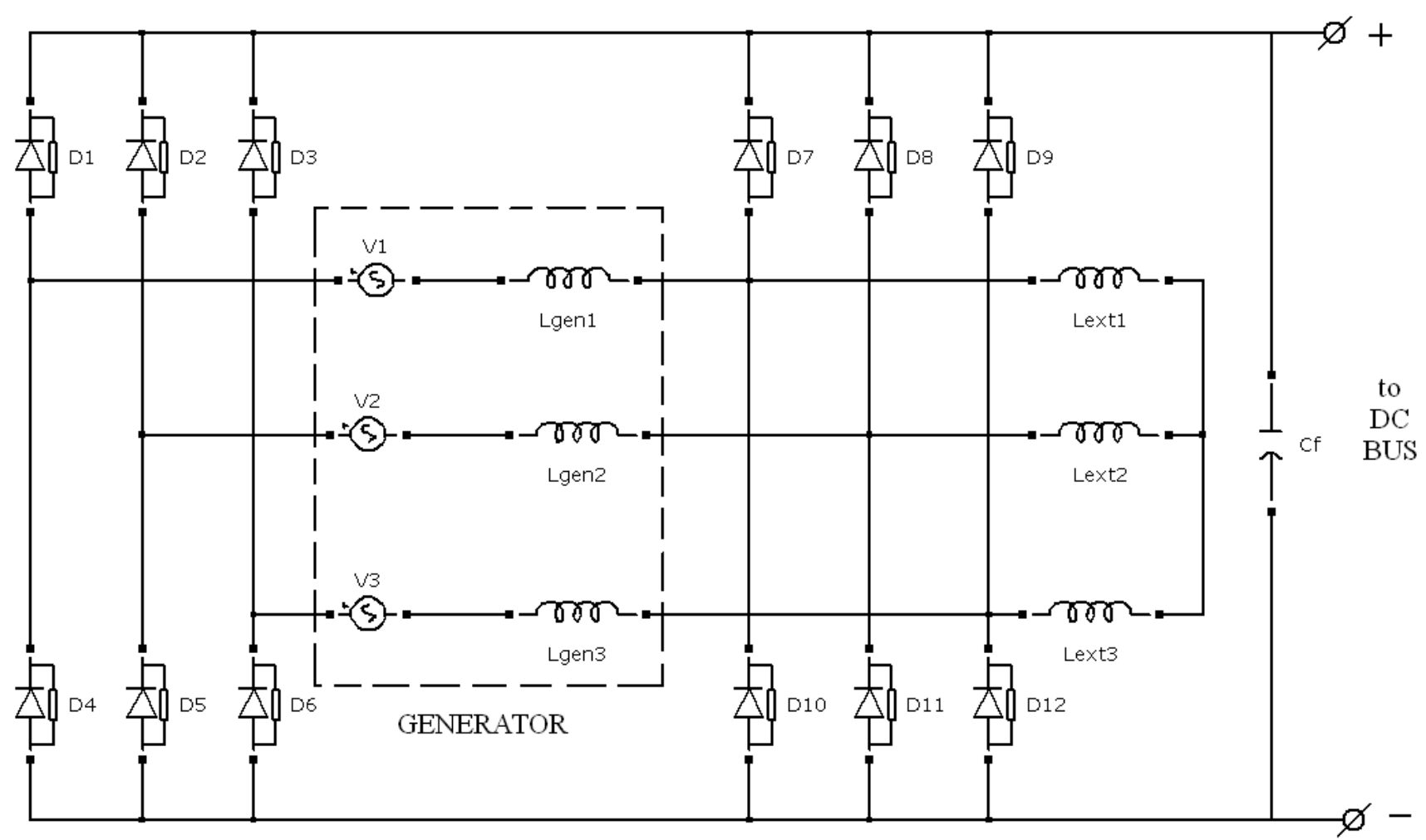

Fig. 2. Passive converter simulation scheme.

Significant improvement can be achieved with automation of the already developed methodology. Because of the number of developed circuits for passive converter topology the program code should be flexible and with minor changes applicable for all solutions included in the patent.

\section{AutOMATED METHODOLOGY - PARAMETERS, VARIABLES AND FLOW CHART}

The circuit shown on fig. 1. has been analyzed in several scientific publications [6], [7]. The aim is $100 \mathrm{~kW}$ electrical output power. Due to mechanical losses from friction torque the output electrical power in the simulations is increased by $10 \%$.

There are two specifics that need to be mentioned. First one is the second three phase full wave rectifier on the right side of the windings of the generator. This way a full wave bridge rectification is achieved on every phase. The second one is the externally connected inductors to every winding as well. The three inductors are connected in star point.

The research uses an electric generator with possible connection of both ends of the windings. This means six output wires from the generator.

This is the reason for creation of different model of the generator than the one included in the libraries. The model is consisting of three alternating voltage sources, 120 degrees shifted and inductors which represent the inductance of the every phase winding.

There are several input parameters to be determined in order to define the wind turbine.

\section{A. Input/Output data} Input data:

a) Pgen - nominal power of the electrical generator of the wind turbine;

b) Fnom - nominal value of the frequency (it can be converted in rpm) of the rotor at nominal power;

c) $\mathrm{EMF} / \mathrm{F}$ - coefficient of the electromagnetic force per one Hertz;

The results are kept in output file of the program and also stored graphically.

Output data:

a) Lgen - output value for the inductance of the winding of the electrical generator;

b) Lext - output value of the inductance of the external inductor.

Depending on the software, the model of the rectifying diodes can be unified and allows development of wide range output power for the wind turbine generator (MATLAB Simulink for example).

The output data for Lgen from the research is used as a guide to the designer of the electrical generator for the wind turbine. Synchronous generator with permanent magnets is developed for the research.

\section{B. Flow chart of the algorithm}

The algorithm can be described in the following steps:

- a mathematical representation of the cubic curve Pcub build with the first equation is the guiding line for the comparison.

$$
\text { Pcub },[W]=\left[\frac{F a}{F n o m}\right]^{3} * \text { Pgen }
$$

,where $\mathrm{Fa}$ is the current value of the frequency. The curve is stored as points of the power in a matrix with certain length;

- the points of the output power of the electrical generator are evaluated by the second equation and stored 
in second matrix with the same length;

$$
P,[W]=U_{p 1} * I_{p 1}+U_{p 2} * I_{p 2}+U_{p 3} * I_{p 3}
$$

,where $\mathrm{U}_{\mathrm{p} 1}, \mathrm{U}_{\mathrm{p} 2}, \mathrm{U}_{\mathrm{p} 3}$ are the voltages of every phase of the generator and $\mathrm{I}_{\mathrm{p} 1}, \mathrm{I}_{\mathrm{p} 2}, \mathrm{I}_{\mathrm{p} 3}$ are the currents which flow through every phase.

- comparison between the two matrixes;

a conditional operators (if/then/else) are used to determine the next action. If the output power at some of the points is higher than the guide line then there is increase of the values of Lext and Lgen with coarse adjustment step of $10 \mathrm{mH}$. In order to build the output curve in correspondence of the principle of work of passive converter circuit there are high frequency and low frequency areas which can be distinguished. The lower part of the graph is determined by Lext and the higher by Lgen. The coarse increase of their values continues until the two curves cross at every point and no power point is higher than any point of Pcub. The fine adjustment is done after the coarse and it uses step of $1 \mathrm{mH}$. This optimization algorithm is based on steepest descent method. The flow chart is shown on fig. 3 .

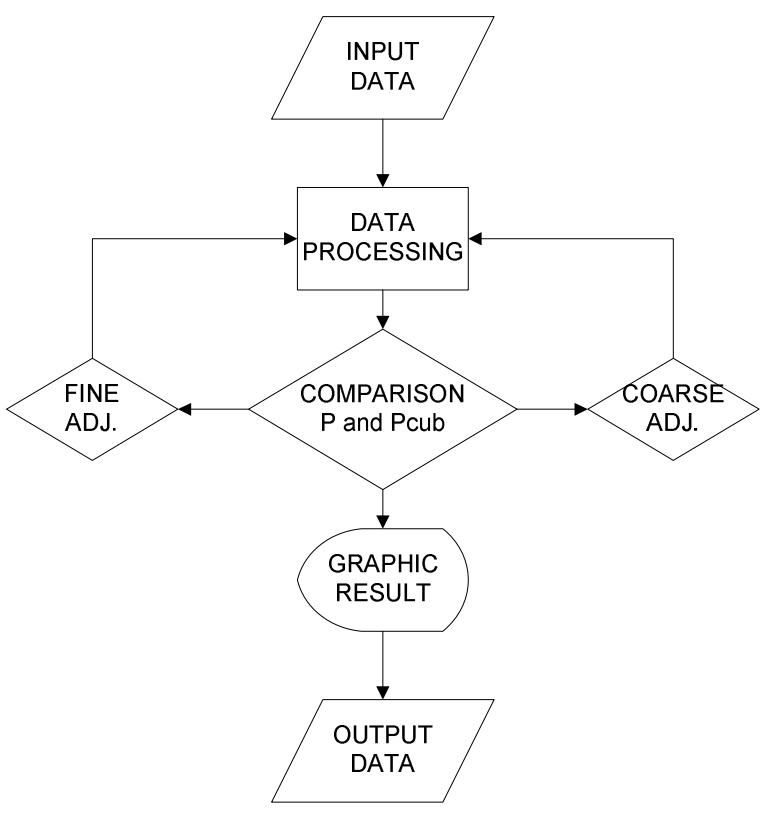

Fig. 3. Flow chart of the automated methodology.

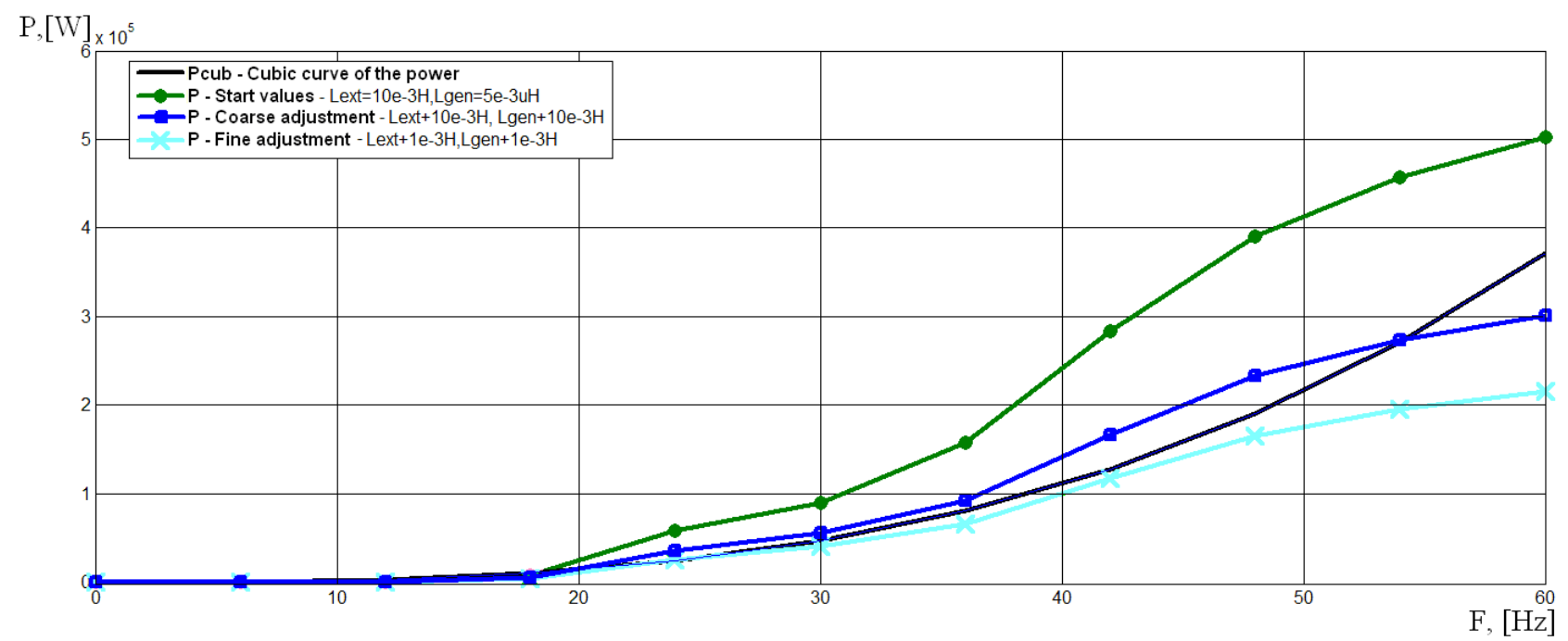

Fig. 4 Graphical results from several iterations with the automated algorithm

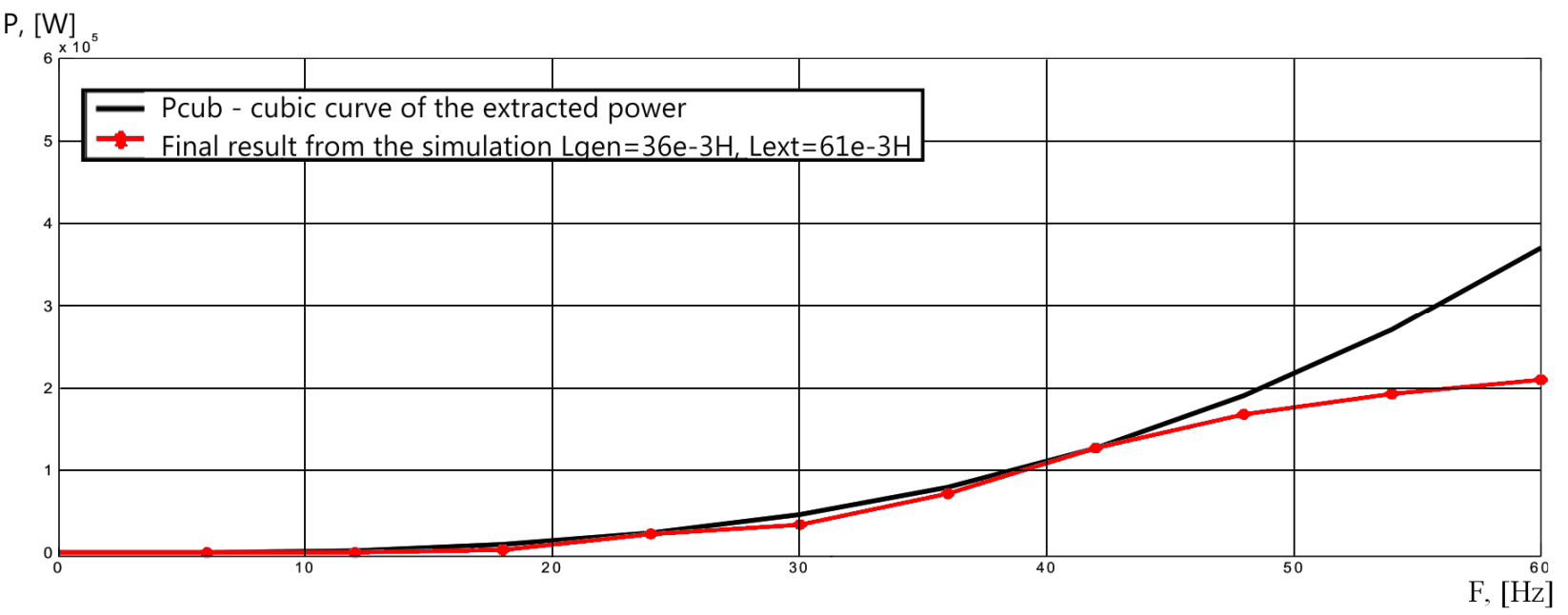

Fig. 5 Graphical final result with the automated algorithm 


\section{GRAPHIC RESULTS}

Figure 4 shows the output power/frequency curves obtained through a simulation done in MATLAB Simulink and describe graphically the principle of work of the algorithm. The guide line Pcub is compared with the curve with the start values for Lgen and Lext. The second iteration starts with the new values for the reactive components and gives another output curve for comparison. Other iterations aren't shown, but as an example it is shown a fine adjusted curve. Final result of the adjustments is given on fig. 5. The final output values are Lgen $=36 \mathrm{mH}$ and Lext $=61 \mathrm{mH}$.

\section{EXPERIMENTAL SET-UP RESULTS AND VERIFICATION OF THE METHODOLOGY}

The experimental set-up is scaled down version of the previous simulations, [5]. The ratio is $100: 1$, so a $1 \mathrm{~kW}$ electrical power is expected as an output. The generator is not with permanent magnets but synchronous with cage rotor coupled to a DC motor which is recreating the wind.

The block scheme shown on Fig. 6 consists of several main components. Control of the rotational speed of the DC motor is accomplished by an adjustable three phase autotransformer combined with three phase rectifier. The excitation windings of the generator and motor are fed by variacs with rectifiers.

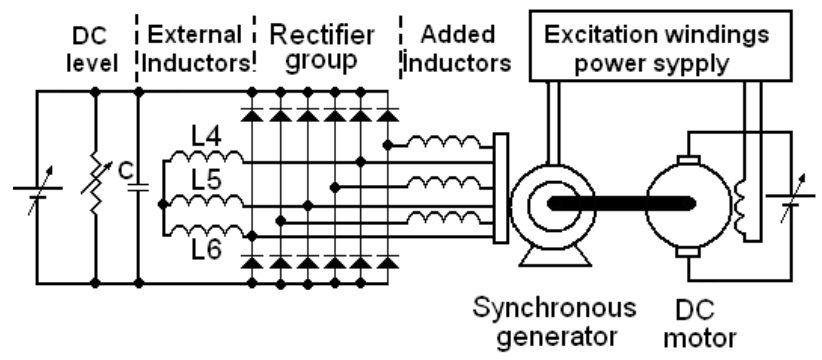

Fig. 6 Block scheme of the test setup

The passive converter circuit is connected to the synchronous generator. The added inductances are also attached to every phase winding.

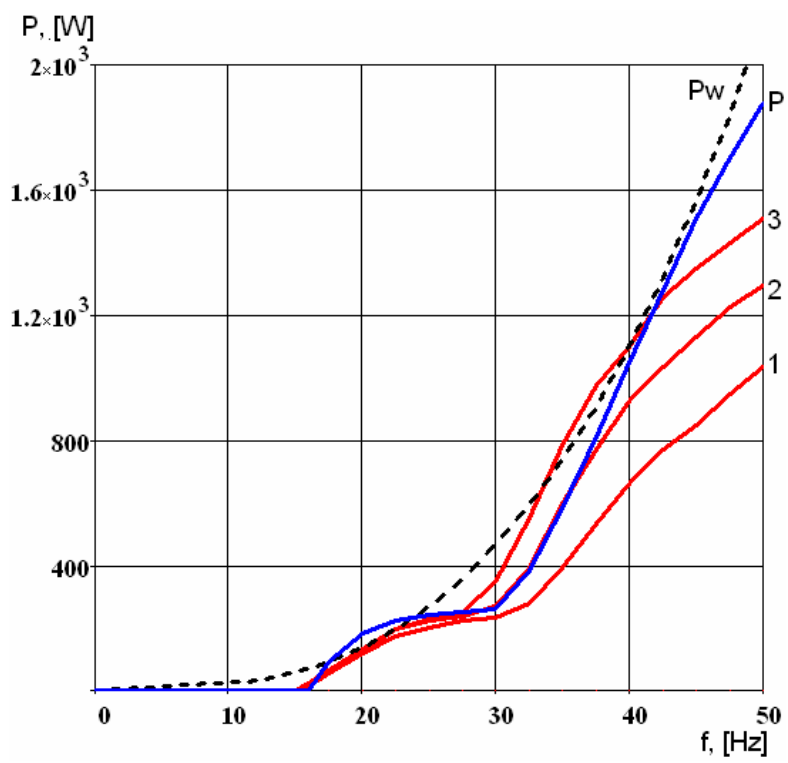

Fig. 7: Comparison between scaled set up and computer simulation
Legend of the curves used in the power/frequency test: $\mathrm{Pw}$ - ideal wind turbine power-frequency curve,

1, 2, 3 - Curves obtained from the experimental set-up, with different values of the added inductors [5],

$\mathrm{P}$ - Obtained power-frequency curve from scaled down computer simulation computer.

The non-linearity in the inductive elements can be designed not to disturb the output characteristic. At low frequency the current is limited and at high frequency the voltage is limited. The non linearity of the generator will affect slightly the characteristic, but it is also possible to adapt the characteristic.

The scaled set-up worked as expected and on Fig 7 is shown the graphical comparison between practical realization and computer simulation.

The computer simulation in Capture/PSpice uses the same values of the components that are evaluated for the test set-up.

At low rotational speed, the curves are almost identical. At the middle section, there is a certain match between curve 2 from the practical test and the simulation power curve. At the high frequency area, the synchronous generator has a power drop. This could be explained with the influence of the desaturation (armature reaction) by high current. The use of a PMSG will reduce these deviations of the simulated curves and experiment.

\section{CONCLUSION}

The presented automated methodology achieves optimized design time for the passive converter circuits described in patent PCT/EP2010/055637. With minor changes the proposed solution is applicable for all the circuits in the patent. The results from the methodology show that the variable speed operation of the wind turbine generator has high efficiency and the passive converter is rival for the active controlled rectifier topology.

\section{ACKNOWLEDGEMENT}

The carried out research is realized in the frames of the project BG051PO001-3.3.06-0005, Program 'Human Resources Development', Ministry of education, youth and science, Bulgaria.

\section{REFERENCES}

[1] M. Patel, "Wind and Solar power systems", CRC Press, 1999, ISBN 0-8493-1605-7, pp. 210-223.

[2] Paul Gipe, "Renewable Energy for Home, Farm, and Business", Chelsea Green Publishing Company, 2004, ISBN 978-1-93149814-2, pp. 345-349.

[3] Johan Morren, Grid support by power electronic converters of Distributed Generation units, Gildeprint B.V., Enschede, The Netherlands, 2006, ISBN: 90-811085-1-4, pp. 11-24.

[4] N. Mohan, Power electronics SE, John Wiley \& Sons, Inc., 2003, ISBN 978-0-471226-93-2, pp. 79-120.

[5] Alex Van den Bossche, Plamen Yankov, Vencislav Valchev, 'Design of Passive Converter for Wind Driven Generators', "EPEPEMC'11", Birmingham, UK, 30 August - 1 September, 2011, ISBN/ISSN: 978-1-61284-167-0, pp. 1-10

[6] P. Yankov, V. Valchev, "Power/Frequency Characteristics of Passive Controlled Wind Turbines with Additional Reactive Components in the Circuitry", "Electronics 2010 Conference", Sozopol, Bulgaria, 22-24 September, 2010, ISSN 1313-1842, pp. 176-179.

[7] 7. Vencislav Valchev, Plamen Valentinov Yankov. Improvement on Passive Controlled Wind Turbines Schematics and Obtaining Power/Frequency Curves, "Electronics 2010 Conference", Sozopol, Bulgaria, 22-24 September, 2010, ISSN 1313-1842, pp. $180-183$. 